\title{
$\Omega$
}

Antonio Artigas, Julie-Lyn Noël, Laurent Brochard, For affiliation details, please Jamiu O. Busari, Dominic Dellweg, Miguel Ferrer, Jens Geiseler, Anders Larsson, Stefano Nava, see the Acknowledgements section

A. Artigas: Critical Care Center, aartigas@tauli.cat Sabadell Hospital, Corporació Sanitaria Universitaria Parc Paolo Navalesi, Stylianos Orfanos, Tauli, Universitat Autonoma de Paolo Palange, Paolo Pelosi, Gernot Rohde, Bernd Schoenhofer, Theodoros Vassilakopoulos, Barcelona, Spain.

\section{Respiratory Critical Care HERMES: European curriculum recommendations}

As intensive care medicine has progressed and advanced in terms of technology, diagnostics and therapeutics, the demand for intensive care medicine has increased continuously, resulting in pressures on resources and healthcare budgets. For these reasons, there is a need to create adequate legal and administrative structures, plus an increasing requirement for qualified specialised personnel and internationally standardised, mutually recognised training programmes [1]. This is especially relevant considering the multidisciplinary nature of intensive care medicine.

Bearing this in mind, a way forward for intensive care medicine is to involve more respiratory physicians because they can be significant providers of care to critically ill respiratory patients [2]. Intermediate care units providing noninvasive monitoring and noninvasive ventilation allow a more efficient and cost-effective approach without decreasing the quality of care or adversely affecting outcome [3]. They make it possible for patients with respiratory diseases of intermediate severity to be cared for in specialised units headed by respiratory physicians [4]. The development of weaning centres and long-term care facilities, including home ventilation, provide important economic advantages that decrease the burden on regular intensive care units (ICUs) by reducing admissions and facilitating discharge to step-down areas [1]. The respiratory physician can provide advantages to patients in these critical care settings, adapting relatively easily to the needs of the patient [2].

Historically in Europe, respiratory physicians have not usually been in the forefront of caring for the critically ill respiratory patient. This is in contrast with the situation in the USA, where pulmonologists are among the first specialists to participate in the treatment of ICU patients [5]. There is however a growing interest in Europe for the role of the respiratory physician, reflected by a trend towards collaboration between intensive care specialists and respiratory medicine specialists. This is manifested by joint consensus papers and employment of respiratory physicians in ICUs [6]. In response to this trend and the growing importance of the role of the respiratory physician, the Respiratory Intensive Care Assembly of the European Respiratory Society (ERS) and the ERS Education Committee have supported the creation of a Respiratory Critical Care HERMES (Harmonised Education in Respiratory Medicine for European Specialists) Task Force.

The ultimate aim of the Respiratory Critical Care HERMES Task Force is to ensure that the best quality of care is delivered through harmonised educational standards in the context of these evolving medical and economic demands. It also aims to address
Statement of Interest Julie-Lyn Noël is an employee of ERS. 
the challenge of harmonising an educational programme in a multitude of European countries with major differences in respiratory critical care delivery, training infrastructures and certification standards.

In order to strengthen the role of the respiratory physician, the Task Force will contribute harmonised educational standards and a training framework in respiratory critical care medicine. These educational standards for training and certification will be consensus based and will follow the methodology of the previous ERS HERMES initiatives, established in 2005, including adult respiratory medicine, paediatric respiratory medicine, spirometry, respiratory sleep medicine, thoracic oncology and respiratory physiotherapy. These initiatives have followed or are following the same development strategy with four key phases (fig. 1): 1) syllabus; 2) curriculum; 3) European assessments and certification; and 4) training centre and training network accreditation (fig. 1) [7-11].

In 2012, the Respiratory Critical Care HERMES Task Force published a European syllabus for training in respiratory critical care medicine [12]. This report presents the Task Force's work to produce European curriculum recommendations in respiratory critical care. The curriculum represents an effort attempts to operationalise the syllabus and includes consideration of educational processes: mainly teaching, learning and assessment.
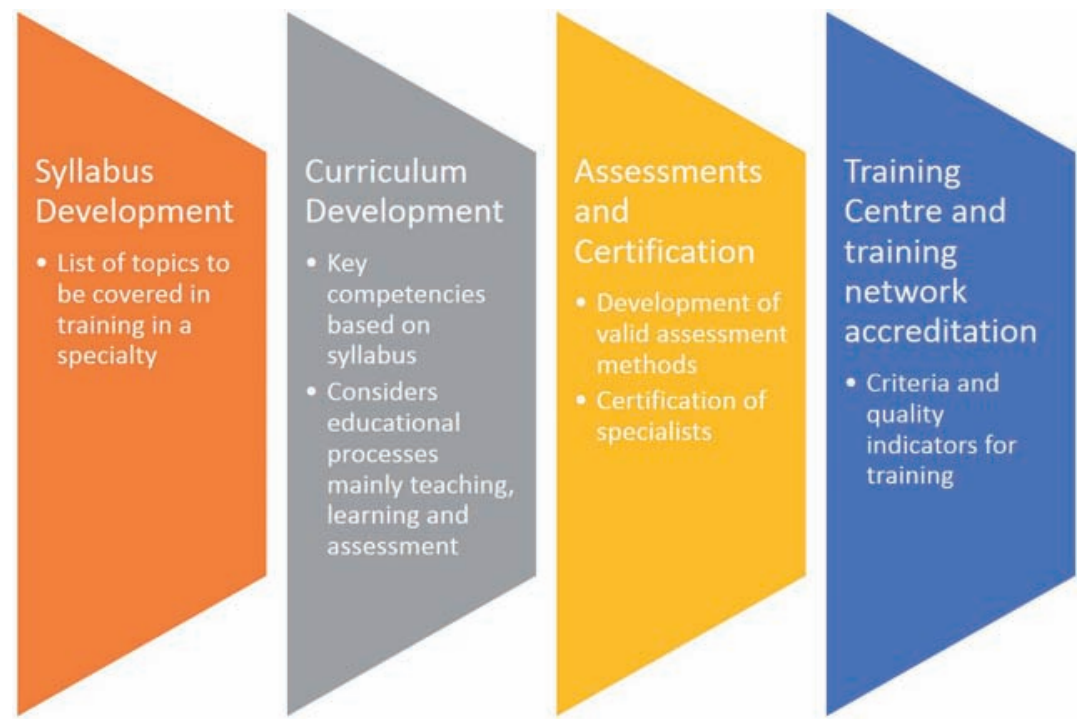

Figure 1

HERMES development strategy.

\section{Curriculum development}

\section{Approach and methodology}

The approach, methods and processes used in the adult respiratory medicine HERMES and paediatric respiratory medicine HERMES curricula were adapted to the needs of a training programme in respiratory critical care. The rationale of the European curriculum recommendations for training in adult respiratory medicine, published in 2008, was used as a basis to develop a curriculum in respiratory critical care [13]. The approach for including content and organisation was drawn from the European curriculum recommendations for training in paediatric respiratory medicine published in 2010 [14].

\section{Task Force participants}

As with the paediatric group, the critical care curriculum phase began with a workshop on curriculum development in January 2012 in Barcelona, Spain which was facilitated by J. Busari (Maastricht University, Maastricht, The Netherlands) who is the ERS medical education advisor. $\mathrm{He}$ is a medical educationalist and also qualified as a general paediatrician. He advised the Task Force members and provided guidance throughout the process. Curriculum development was coordinated by J-L. Noël (ERS Headquarters, Lausanne, Switzerland) who provided methodological, administrative, clerical and logistical support for all participants. The Task Force members, field experts in respiratory critical care with a particular interest in training, formulated 20 curriculum modules based on the syllabus. National respondents selected through the Forum of European Respiratory Societies were consulted and have contributed to the content of the curriculum. Together with the Task Force members, they constitute the expert panel which validated actual practices in their respective countries (fig. 2).

\section{European training concept}

The educational needs to be met by the training programme are expressed in the European training concept as agreed by the Task Force participants at the outset. The 
curriculum defines competencies for adult respiratory physicians who are not directly involved in multidisciplinary intensive care medicine but who will deliver respiratory critical care. This can be regarded as a training framework in respiratory critical care medicine. Respiratory critical care medicine is regarded as an additional qualification open to all physicians specialised in adult respiratory medicine with competencies dealing with intermediate intensive care units or specialised units dedicated to the care of critically ill respiratory disease patients. Access to training and additional qualification in respiratory critical care can also be open to other related specialties. It must be emphasised that the competencies suggested by the Respiratory Critical Care HERMES Task Force are not sufficient for general medical or surgical intermediate/ intensive care units, but could be used as a step-up process with additional periods required to acquire competences for multidisciplinary critical care in addition to respiratory critical care [15]. This guided the reflections on the content of the curriculum modules.

\section{Expected learning outcomes and elements of the curriculum}

A common structure based on the paediatric curriculum with some adaptation and improvement was agreed upon during the workshop in curriculum development (fig. 3).

The following elements are included in each module, and served as a guide for the participants to complete and facilitate the process. These elements articulate the expected learning outcomes in the training framework.

\section{General theme/objective}

The general theme/objective aims to unify all the elements in the curriculum module. This gives an overview of the learning outcomes both for the trainer and trainee.

\section{Syllabus item}

Each syllabus item is drawn from the European syllabus published in 2012. A few additions and deletions were incorporated due to recent studies and changes in practice.

\section{Knowledge}

These items are learning outcomes that are cognitions, ideas or concepts that are expected to be learnt.

\section{Skills}

These items are learning outcomes that are cognitive skills and psychomotor-perceptual skills. Cognitive skill is the ability to utilise the learned ideas or concepts when faced with a problem. Psychomotor-perceptual skills are the physical or perceptual competencies the trainees are expected to possess after the training.

\section{Attitudes and behaviour}

These items are learning outcomes that can demonstrate affective skill, which is the ability to exhibit actions that reflect certain desired behaviour [16].

\section{Level of competence}

The levels of competence agreed upon in the syllabus phase were adopted into the curriculum framework (table 1).

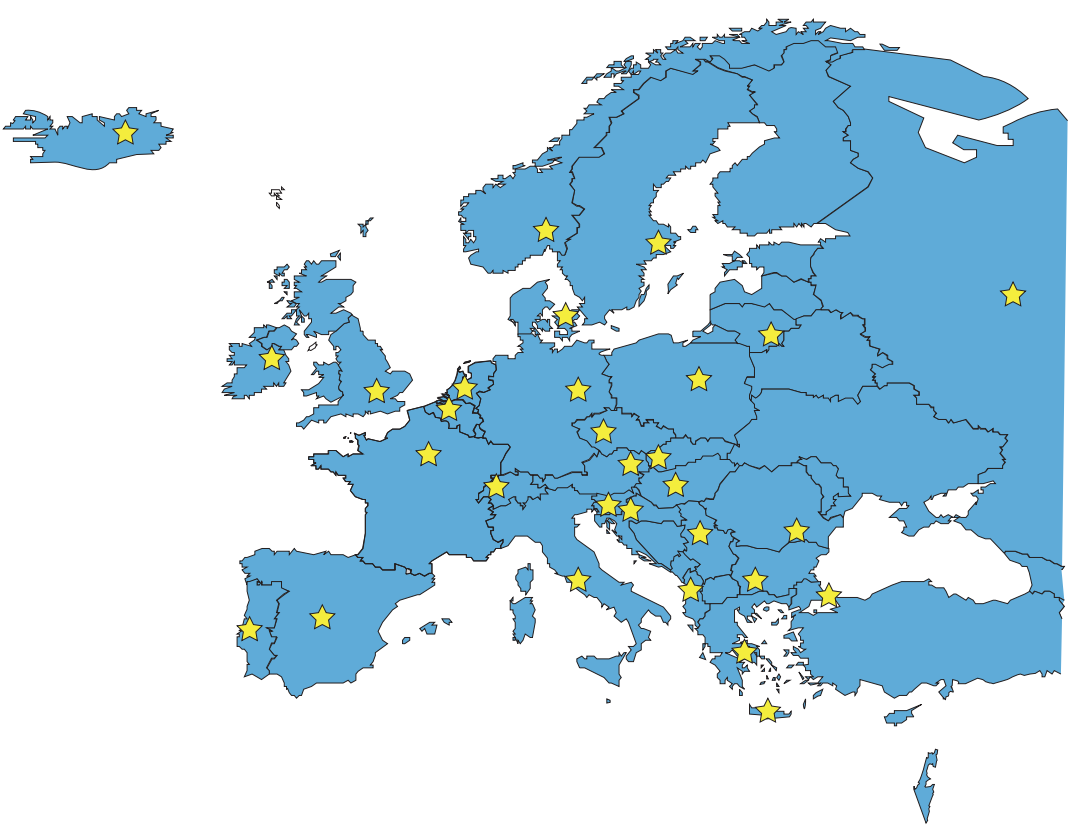

Figure 2

European representation of respiratory critical care HERMES participants. Countries represented: Albania, Austria, Belgium, Bulgaria, Croatia, Cyprus, Czech Republic, Denmark, France, Germany, Greece, Hungary, Iceland, Ireland, Italy, Lithuania, Netherlands, Norway, Poland, Portugal, Romania, Russian Federation, Serbia, Slovakia, Slovenia, Spain, Sweden, Switzerland, Turkey, UK. 


\begin{tabular}{|c|c|c|c|c|c|c|c|}
\hline \multirow{2}{*}{$\begin{array}{l}\text { Global } \\
\text { Theme/Objective: }\end{array}$} & \multicolumn{7}{|c|}{ At the end of this module, the trainee should be able to evaluate and identify respiratory failure and manage accordingly. } \\
\hline & Knowledge & Skills & Attitudes and Behaviour & 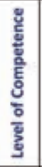 & $\begin{array}{l}\text { Minimum Clinical/Educational } \\
\text { Exposure }\end{array}$ & Assessment Tools & Sample Clinical Situation \\
\hline $\begin{array}{l}1 \text { Acute respiratory } \\
\text { failure (ARF) }\end{array}$ & $\begin{array}{l}\text { - Physiology, pathophysiology of } \\
\text { acute respiratory failure } \\
\text { - Respiratory pump function and } \\
\text { dysfunction } \\
\text { - Blood gas analysis (BGA) } \\
\text { - Difference between hypoxia and } \\
\text { hypoxaemia } \\
\text { - Imaging (e.g. Chest X-ray) } \\
\text { - National and international } \\
\text { guidelines for treatment of ARF }\end{array}$ & $\begin{array}{l}\text { - Evaluation, performance, } \\
\text { interpretation, and reporting of } \\
\text { blood gas analysis, } \mathrm{O}_{2} \text { saturation, } \\
\text { transcutaneous } \mathrm{CO}_{2} \text { measurement } \\
\text { and Chest } \mathrm{X} \text {-ray (imaging) and } \\
\text { lung/chest wall mechanics }\end{array}$ & $\begin{array}{l}\text { - Willingness to accept } \\
\text { supervision } \\
\text { - Willingness to explain and } \\
\text { discuss diagnostic and } \\
\text { treatment strategies }\end{array}$ & 3 & $\begin{array}{l}\text { - Participate in a workshop } \\
\text { dealing with the basics in } \\
\text { identification and management } \\
\text { of ARF }\end{array}$ & $\begin{array}{l}\text { - CbD } \\
\text { - DOPS } \\
\text { - MiniCEX }\end{array}$ & $\begin{array}{l}\text { - Management of a patient with acute } \\
\text { severe pneumonia }\end{array}$ \\
\hline $\begin{array}{l}1.1 \text { Hypoxaemic } \\
\text { respiratory failure } \\
\text { including acute } \\
\text { respiratory distress } \\
\text { syndrome }\end{array}$ & $\begin{array}{l}\text { - Causes of hypoxaemic ARF } \\
\text { - Definition and classification of } \\
\text { acute respiratory disease syndrome } \\
\text { (ARDS) } \\
\text { - Ventilator and tube associated } \\
\text { complications } \\
\text { - Ventilator-induced Iung injury } \\
\text { (VILI) and intubation associated } \\
\text { pneumonia (IAP) } \\
\text { - Protective mechanical ventilation }\end{array}$ & $\begin{array}{l}\text { - Identification and management of } \\
\text { hypoxaemic ARF } \\
\text { - Indication of non-invasive } \\
\text { ventilation (NIV) in hypoxaemic ARF } \\
\text { - Risk assessment and management } \\
\text { of NIV failure and indication of } \\
\text { intubation } \\
\text { - Intubation and invasive mechanical } \\
\text { ventilation }\end{array}$ & & 3 & $\begin{array}{l}\text { - Participate in the management } \\
\text { and setting the ventilator in } 20 \\
\text { patients with hypoxaemic } \\
\text { respiratory failure }\end{array}$ & $\begin{array}{l}- \text { COD } \\
\text { - DOPS } \\
\text { - MiniCEX }\end{array}$ & $\begin{array}{l}\text { - Management of patient with } \\
\text { hypoxaemic respiratory failure } \\
\text { including acute respiratory distress } \\
\text { syndrome }\end{array}$ \\
\hline
\end{tabular}

\section{Figure 3}

Example of the module layout: respiratory failure module.

\section{Minimum clinicalleducational exposure}

Minimum clinical/educational exposure can relate to different aspects, such as duration ofthe programme or rotation, attendance atworkshops or postgraduate courses, number of cases seen, number of procedures performed and certain specific actions which lead the trainee to the learning outcomes.

\section{Assessment methods}

Assessment is a key feature of any educational programme. It is important for trainees to understand how and what they are learning. They can then relate this to the assessment process. The Task Force approached assessments by using the assessment toolbox first introduced in the curriculum development of the paediatric HERMES (table 2) [14].

\section{Sample clinical situation}

A clinical situation that gives practical example of how the different elements of the curriculum can be applied in a typical clinical setting. Sample clinical situations were not given for the practical skills module, which instead refer to the relevant module where the practical skills are applied and/or mentioned, and the prevention module, which collates examples of prevention cited throughout the curriculum modules.

\section{Processes}

As mentioned, the curriculum phase began with a workshop facilitated by J. Busari in January 2012 in Barcelona, Spain where the common structure and elements were agreed on by the Task Force members. A discussion on each element followed in order to ensure the understanding of each Task Force member, as curriculum developers, and to facilitate the whole process. Once concepts were clearly defined and clarified, the Task Force divided into small working groups, and with electronic exchange, worked on the completion of 19 modules based on the syllabus.

Table 1 Levels of competence

\section{Definitions}

Level 1: foundation competency to be used in daily practice by everybody involved in the field. It is a requisite to function in the multidisciplinary team/setting

Level 2: intermediate competency to be demonstrated or applied with consultation within the multidisciplinary team

Level 3: specialised competency which has the highest level of complexity and specialisation 
Table 2 Assessment toolbox

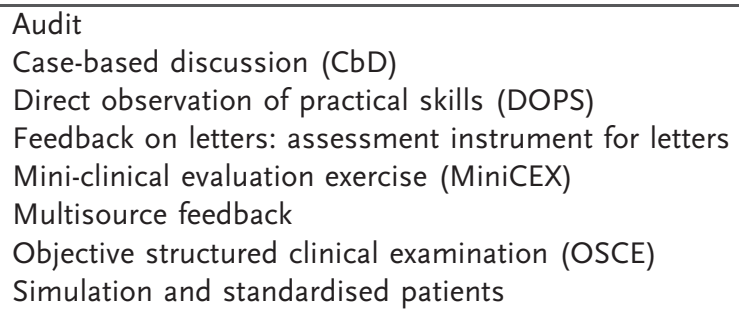

The Task Force met again in September 2012 in Vienna to discuss and adapt the 19 modules. The main focus was to debrief on the difficulties encountered in the process of completion and adapt the modules accordingly. Further work ensued and the group met again in February 2013 to complete all the elements to ensure that each item was specific, measurable, achievable, realistic and timely.

With the completed modules, the layout and content have been changed for consistency. Repetitions have been checked across all the modules. The practical skills module referred to relevant module items where the practical skill is applied instead of including a sample clinical situation. Levels of competence and minimal exposure were checked that they are consistent with the initial Delphi process of the syllabus items and the European training concept in respiratory critical care. Sample clinical situations were modified according to the level of specificity required.

After all these final modifications, the group met finally in September 2013 to discuss the final draft where minimal changes in some items were discussed and modified as necessary. The group agreed also to create a final module on prevention, citing examples from across all the modules throughout the curriculum. The final draft of the curriculum was sent to all the national respondents who had participated in the syllabus development phase. They gave valuable feedback and comments and the curriculum was modified and adapted accordingly. An overview of the whole process is shown in figure 4.

\section{Results}

The result of the extensive processes undertaken by the Task Force are the 20 curriculum modules (table 3 ).
These modules are designed to provide a concise, straightforward and user-friendly framework for training in respiratory critical care. The curriculum modules set out the integration of the defined learning outcomes and serve as a guide to the educational experience and opportunities in respiratory critical care.

\section{Discussion}

\section{Assessment methods}

The pragmatic approach of the paediatric HERMES Task Force on assessments was adopted. Their shortlist of assessment methods in the toolbox was checked by the curriculum participants in terms of its acceptability, applicability and usefulness in the context of each syllabus item and line in the curriculum module. However, for the exercise in respiratory critical care HERMES, simulation was recommended as an assessment tool in many instances such as for invasive mechanical ventilation, extracorporeal

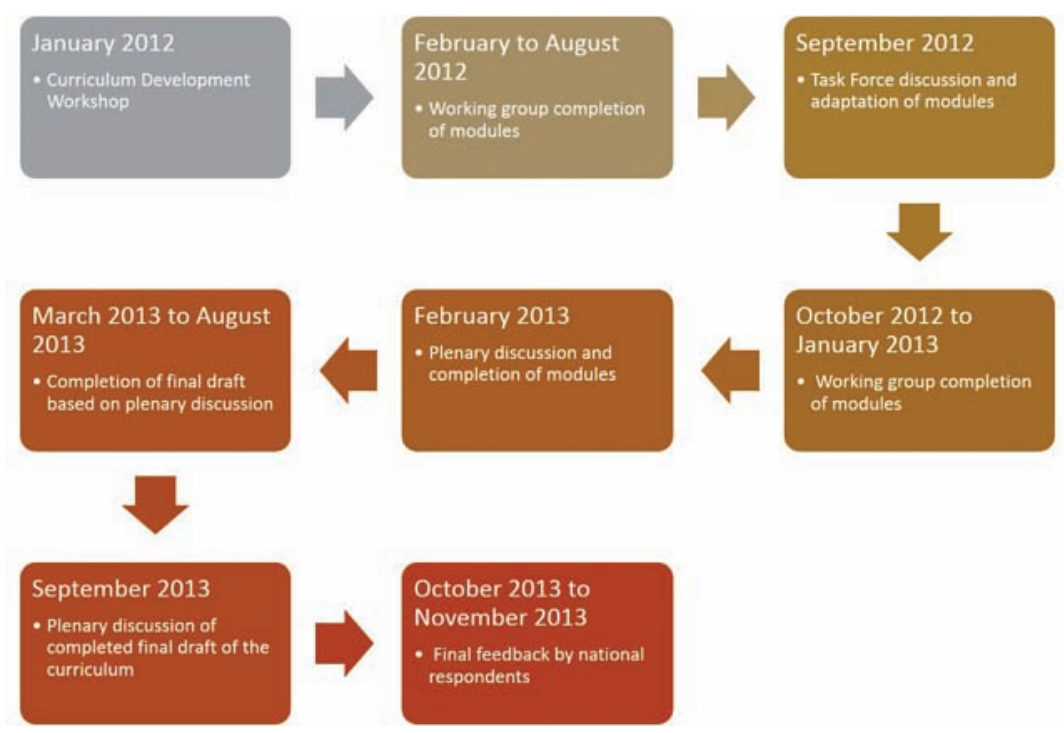

Figure 4

Respiratory Critical Care HERMES curriculum processes. 
membrane oxygenation, airway maintenance, noninvasive ventilation, shock syndromes, pulmonary oedema, vasoactive and inotropic therapy, haemodynamic effects, drug dosing in renal failure and triage. Examples and recommendations on how to integrate simulator systems exist and it is the intention of the Task Force to integrate these into respiratory critical care training. [17].

\section{Minimum clinical/educational exposure}

The Task Force failed to reach consensus on minimum clinical exposure for a few items. Some numbers were reviewed and modified taking into account generalisability, and the balance between applicability and acceptability (i.e. that the training centre is able to deliver the minimum requirement and that the minimum requirement is acceptable). For this, each Task Force member had to think about their own environment and context to check against. For example, in the case of significant pulmonary haemorrhage in the respiratory physiology and pathophysiology module, a minimum clinical exposure of treating/triaging five patients instead of 10 was agreed upon. Some argued that this is a rare condition in a general ICU, at least in the Scandinavian countries. In some other instances, a decision was made to eliminate a number of procedures and to replace them with an educational exposure as appropriate for training in respiratory critical care. An example of this would be in the immunology and transplantation module where attendance on a postgraduate course or seminar is recommended.

With regards to consistency within respiratory critical care, of note is the instance where minimum exposure specifies evaluation of laboratory results as in the case for disseminated intravascular coagulation where the level of competence is at 1 (see table 1 for definitions of level of competence). In the acute gastrointestinal and abdominal disorders module, the syllabus item on prevention, treatment and principles of gastrointestinal bleeding, the minimum exposure of participation in the management of gastrointestinal bleeding in at least 10 patients was recommended. The level of competence for this item is at 2 .

\section{Strategies for implementation}

Throughout the curriculum development, great care was taken to ensure transparency

\section{Table 3 Curriculum modules}

1. Respiratory physiology and pathophysiology

2. Respiratory failure

3. Respiratory medical and surgical conditions

4. Ventilation and airway management

5. Other respiratory therapies

6. Cardiovascular disorders

7. Renal disorders

8. Central nervous system disorders

9. Metabolic and endocrine effects in critical illness

10. Infectious diseases

11. Acute haematologic and oncologic disorders

12. Acute gastrointestinal and abdominal disorders

13. Environmental hazards

14. Immunology and transplantation

15. Monitoring, quality control and biostatistics

16. Practical skills

17. Management

18. Communications and ethics

19. Basics of evidence-based medicine and research

20. Prevention

of the process and that input from all involved was obtained in order to increase acceptability and applicability of the end product i.e. curriculum recommendations and framework.

According to an additional survey sent to all national respondents during syllabus development in September 2010, it was found that respiratory critical care medicine is taught as a subspecialty of pulmonology or respiratory medicine, and not a specialty of its own. Training periods vary between 3 months and 1 year [7]. In Cyprus, a syllabus based on the relevant sections of the CoBaTriCE training framework is used [18]. Doctors in some countries, such as Iceland, often travel, for example to the USA, to gain respiratory critical care qualifications as these are officially recognised in their country.

This curriculum therefore defines specific competencies and provides a usable framework in the training of clinicians in respiratory critical care and aspires to set the stage for consolidation of an additional qualification and competence in respiratory critical care medicine. We hope that it is a starting point and useful guide for countries to foster educational development activities in respiratory critical care. It is also intended that the participants of the exercise, i.e. Task Force members and national respondents, 
will be able to propose educational development activities in their respective countries by approaching their national authorities.

\section{Conclusion}

The European curriculum recommendations for training in respiratory critical care medicine mark the next milestone in the Respiratory Critical Care HERMES initiative. The third milestone on assessments is currently being prepared. The next challenge for the Task Force is to formulate an assessment framework using valid methods of competency assessment. Many other challenges remain, including faculty development, and the future task of developing training networks across Europe with accreditation activities.

In parallel, this curriculum also serves as groundwork for collaborative interactions with other societies involved in intensive care medicine in which hopefully the ERS can participate in a multisociety effort to help foster the profession. intensive care medicine has a multidisciplinary approach in many countries: a survey of the European Society of Intensive Care Medicine (ESICM) showed that in 10 out of 19 European countries there is a multidisciplinary approach to intensive care training with a common core curriculum. 17 countries out of the 19 offer an official registration for special competence in intensive care medicine, and in 16 countries out of these 17 , this accreditation is combined with a base or major specialty, such as anaesthesia, internal medicine, surgery and paediatrics [19]. The European Union of Medical Specialists (UEMS) has also made a large step forward in this regard, creating the Multidisciplinary Joint Commission for Intensive Care Medicine encouraging involvement of all specialties involved in intensive care medicine [20]. Respiratory medicine is envisaged to be one of these base or major specialties that can be accredited for special competence in intensive care medicine linked with a step-up process of certification in respiratory critical care.

The initiative is working towards realising the European training concept of respiratory critical care medicine specialists. Concrete steps are being taken to ensure that the highest training standards are delivered. With the homogenisation and standardisation of training across Europe, the creation of uniform standards of care for critically ill respiratory disease patients will be implemented. Using the defined key competencies for training respiratory physicians in respiratory critical care, quality control for aspects of training can be realised. With the delivery of valid assessment methods and certification, qualified respiratory physicians can be certified to meet the growing demand. Lastly, with training networks and accreditation, defining quality indicators for staff and infrastructure of intermediate care units, weaning centres and home ventilation can be facilitated. Consistent with the ERS mission to prevent, cure or alleviate suffering from respiratory disease, these milestones ensure the delivery of the very best of care to critically ill respiratory disease patients.

\section{Further reading}

The complete HERMES Critical Care syllabus is available to access at www.ers-education. org/Media/Media.aspx?idMedia $=236215$

\section{Acknowledgements}

Affiliations of the authors are as follows: A. Artigas: Critical Care Center, CIBER Enfermedades Respiratorias, Sabadell Hospital, Corporació Sanitaria Universitaria Parc Tauli, Autonomous University of Barcelona, Barcelona, Spain; J-L. Noël: European Respiratory Society, Lausanne, Switzerland; L. Brochard: Critical Care Department and Keenan Research Centre, St Michael's Hospital, and Interdepartmental Division of Critical Care Medicine, University of Toronto, Toronto, Canada; J. Busari: Medical Residency Program, Department of Pediatrics, Atrium Medical Center, Heerlen, and Department of Educational, Development and Research, Faculty of Health, Medicine and Life Sciences, University of Maastricht, Maastricht, The Netherlands; D. Dellweg: Respiratory and Critical Care Medicine, Kloster Grafschaft, Schmallenberg, Germany; M. Ferrer: Servei de Pneumologia, Hospital Clinic, Villarroel, Spain; J. Geiseler: Chefarzt Klinik für Intensivmedizin und Langzeitbeatmung, Asklepios Fachkliniken München-Gauting, Gauting, Germany; A. Larsson: Hedenstierna Laboratory, Uppsala University, Uppsala, Sweden; S. Nava: Respiratory and Critical Care, Sant' Orsola Malpighi Hospital, Bologna, Italy; P. Navalesi: Università del Piemonte Orientale "A. Avogadro", Dipartimento di Medicina Traslazionale, Novara, 
and SC Anestesia e Rianimazione, Ospedale Sant'Andrea (ASL VC), Vercelli, Italy; S. Orfanos: 2nd Dept of Critical Care, University of Athens Medical School, Attikon Hospital, Athens, Greece; P. Palange: Dipartimento Medicina Clinica, University La Sapienza, Rome, Italy; P. Pelosi: Dept of Surgical Sciences and Integrated Diagnostics, IRCCS AOU San Martino - IST, University of Genoa, Genoa, Italy; G. Rohde: Dept of Respiratory Medicine Maastricht University Medical Center, Maastricht, The Netherlands; B. Schoenhofer: Dept of Pulmonary and Intensive Care Medicine, Klinikum Region Hannover, Krankenhaus Oststadt-Heidehaus, Hannover, Germany; T. Vassilakopoulos: 1st Dept of Pulmonary and Critical Care Medicine, University of Athens Medical School, Evangelismos Hospital, Athens, Greece; A. Simonds: Academic Unit of Sleep and Breathing, Royal Brompton and Harefield NHS Foundation Trust, London, UK.

The following experts participated as national respondents. Bulgaria: D. Osmanliev, K. Kostov, V. Hodgev, O. Georgiev, D. Petkova, Y. Ivanov; Cyprus:
T. Kyprianou, A.Rigas, A.Sergis; Czech Republic: V. Koblížek, J. Chlumský, P. Jakubec, L. Fila, L. Havel; France: J-D. Chiche, A. Rabbat, A. Cuvelier, T. Similowski, O. Sanchez, A. Demoule, C. Pison; Germany : M. Pfeifer, T. Welte; Greece: P. Argiropoulou; Hungary: É. Vizi, G. Böszörményi Nagy, P. Gordana, B. Igor, M. Suzana, M. Kornelija, J. Marko, M. Dubravka, P. Hrvoje; Iceland: G. Gudmundsson, Ó. Einarsson; Ireland: E. Maloney, R. Fahy, E. Moloney, M. Kennedy, A. O'Regan, E. Mulloy, M. Herzig. Italy E. Clini, N. Ambrosino; Lithuania: G. Kekstas, J.Sipylaite, S. Vosylius, A. Radziunas, K. Malakauskas, S. Miliauskas; Portugal: C. Barbara, J.C. Winck, J.Valença, P. Simão, J. Moita, J. Cardoso; Romania: R. Stoica, A. Macri, S. Dumitrache-Rujinski, S.Dan, D. Boisteanu, M. Ciontu; Russia: S. Avdeev, V. Ridnov, A. Vanyushin; Serbia: I. Stankovic, L. Ristic, Z. Lazic, L. Bibic, B. Bulajic, M. Vukcevic Batranovic, L. Sagic, O. Ljiljana; Spain: A. Torres, G. González, L. Blanch, C. León, J. Mancebo, A. Esteban, J. Blanco, F. Baigorri, E. Fernández Mondéjar; Switzerland: J-C. Chevrolet, P. Jolliet, D. Tassaux; UK: J. Bion, A. Rhodes.

\section{References}

1. Respiratory intensive care. In: Gibson GJ, Loddenkemper R, Sibille Y, et al. eds. European Lung White Book. European Respiratory Society, Sheffield, 2013; pp. 358-361.

2. Evans T, Elliott MW, Ranieri M, et al. Pulmonary medicine and (adult critical care medicine in Europe. Eur Respir J 2002; 19: 1202-1206.

3. Nava S, Confalonieri M, Rampulla C. Intermediate respiratory intensive care units in Europe: a European perspective. Thorax 1998; 53: 798-802.

4. Llinàs ES. Respiratory Intermediate care units. Arch Bronconeumol 2008; 44: 1-2.

5. Pneumatikos É. Pulmonology or Pulmonary and Critical Care Medicine. A dilemma for the future. Pneumon 2007; 20: $2 \mathrm{e}$

6. Torres A, Ferrer M, Blanquer JB, et al. Intermediate respiratory intensive care units: definitions and characteristics. Arch Bronconeumol 2005; 41: 505-512.

7. Loddenkemper R, Séverin T, Haslam PL. European curriculum recommendations for training in adult respiratory medicine: crossing boundaries with HERMES. Eur Respir J 2008; 32: 538-540.

8. Gappa M, Noël J-L, Séverin T, et al. European Curriculum Recommendations for Training in Paediatric Respiratory Medicine: one step further. Eur Respir J 2010; 36: 478-479.

9. Steenbruggen I, Mitchell S, Séverin T, et al. Harmonising spirometry education with HERMES: training a new generation of qualified spirometry practitioners across Europe. Eur Respir J 2011; 37: 479-481.

10. Gamarra F, Boffetta P, De Ruysscher D, et al. Thoracic Oncology HERMES syllabus: setting the basis for thoracic oncology training in Europe. Eur Respir J 2013; 42: 1183-1185.

11. Mitchell S, Pitta F, Troosters T. Standardised education and training for respiratory physiotherapists. Breathe 2013; 9: 171-174.
12. Artigas A, Vassilokopoulos T, Brochard L, et al. Respiratory Critical Care HERMES: a European core syllabus in respiratory critical care medicine. Breathe 2012; 8: 217-229.

13. Loddenkemper R, Haslam PL, Séverin T, et al European curriculum recommendations for training in adult respiratory medicine: 2 nd report of the HERMES Task Force. Breathe 2008; 5: $80-93$.

14. Gappa M, Noël J-L, Séverin T, et al. Paediatric HERMES: European curriculum recommendations for Training in Paediatric Respiratory Medicine. Breathe 2010; 7: 72-79.

15. Artigas A, Pelosi P, Dellweg D, et al. Respiratory critical care HERMES syllabus: defining competencies for respiratory doctors. Eur Respir J 2012; 39: 1294-1297.

16. Ratnaplan S, Hilliard RI. Needs assessment in postgraduate medical education: a review. Med Educ 2002; 7: 1-8.

17. Lighthall GK, Barr J. The use of clinical simulation systems to train critical care physicians. J Intensive Care Med 2007; 22: 257-269.

18. European Society of Intensive Care Medicine, 2011. An international Competency Based Training programme in Intensive Care medicine-CoBaTrICE. www.cobatrice.org/Data/ModuleGestionDeContenu/ PagesGenerees/en/o2-competencies/7.asp Date last accessed: 10 December 2013.

19. Bion JF, Ramsay G, Roussos C, et al. Intensive care training and specialty status in Europe: international comparisons. Task Force on Educational issues of the European Society of Intensive Care Medicine. Intensive Care Med 1998; 24: 372-377.

20. Burchardi H. Specialty status for intensive care medicine? Crit Care 1999; 3: R53-R54. 